\title{
вмJ Global Health Towards attainment of Indigenous health through empowerment: resetting health systems, services and provider approaches
}

\author{
Cheryl Barnabe
}

To cite: Barnabe C. Towards attainment of Indigenous health through empowerment: resetting health systems, services and provider approaches. BMJ Global Health 2021;6:e004052. doi:10.1136/ bmjgh-2020-004052

Handling editor Stephanie M Topp

Received 25 September 2020 Revised 20 January 2021 Accepted 26 January 2021

\section{Check for updates}

(c) Author(s) (or their employer(s)) 2021. Re-use permitted under CC BY-NC. No commercial re-use. See rights and permissions. Published by BMJ.

Medicine, University of Calgary Cumming School of Medicine, Calgary, Alberta, Canada

Correspondence to Dr Cheryl Barnabe; ccbarnab@ucalgary.ca

\section{ABSTRACT}

Colonial policies and practices have introduced significant health challenges for Indigenous populations in commonwealth countries. Health systems and models of care were shaped for dominant society, and were not contextualised for Indigenous communities nor with provision of Indigenous cultural approaches to maintain health and wellness. Shifts to support Indigenous health outcomes have been challenged by debate on identifying which system and service components are to be included, implementation approaches, the lack of contextualised evaluation of implemented models to justify financial investments, but most importantly lack of effort in ensuring equity and participation by affected communities to uphold Indigenous rights to health. Prioritising the involvement, collaboration and empowerment of Indigenous communities and leadership are critical to successful transformation of healthcare in Indigenous communities. Locally determined priorities and solutions can be enacted to meet community and individual needs, and advance health attainment. In this paper, existing successful and sustainable models that demonstrate the empowerment of Indigenous peoples and communities in advocating for, designing, delivering and leading health and wellness supports are shared.

\section{INTRODUCTION}

While refraining from imposing a definition, the United Nations recognises Indigenous peoples as those who self-identify and are accepted by their community as their member, with this community having historical continuity to precolonial and/or presettler societies, with distinct cultural practices and social, economic and political systems. ${ }^{1}$ Health systems in communities prior to contact were robust. ${ }^{2-4}$ Regardless of global location, oral history supports a thriving population with longevity and a wholistic view of health. Communities were upheld with traditional roles to support health and strong principles of care and responsibility for each member prevailed.
Summary box

- Current health system structures and approaches are insufficient to resolve health inequities experienced by Indigenous populations.

- Indigenous rights to health and regaining selfdetermination over all aspects of decision-making and service delivery are overarching needs in health system and service transformation.

- Indigenous leadership, community and individual empowerment is a priority for ensuring there is culturally relevant development, implementation and evaluation of health system structures and service delivery.

These health systems were dismantled through colonial and imperial governmental action. ${ }^{5}$ In commonwealth countries such as Canada, the USA, Australia and New Zealand, Indigenous peoples were subjected to systems and models of care shaped for dominant society, which were not contextualised for remote communities and with the exclusion of Indigenous cultural approaches. The existing healthcare systems are heavily oriented to servicing acute illness, leaving management of chronic conditions to be addressed once established or when complications occur, ${ }^{6}$ and with minimal focus on broader concepts of preventive services and health maintenance. Compensation models for facilities and providers in health systems do not support quality care, complex care provision or services beyond a biomedical approach, which are necessary to address inequities in social determinants of health. Health institutions may strive to provide culturally safe care environments which are free of racism and stereotyping and which respect Indigenous patient identity, ${ }^{7}$ but for the most part fail to resource the needed initiatives in processes and staff to do so effectively. ${ }^{8}$ Several examples of discrimination and racism have been 
compiled, with severe consequences of harm and death to Indigenous patients. ${ }^{9}$

The right to resolve these inequities through Indigenous self-determination, development and administration of health programmes, and maintaining the right to access mainstream social and health services without discrimination was declared by the United Nations. ${ }^{10}$ Upholding these rights requires significant transformation of health systems, services and individual providers, which will only be accomplished by demonstrating allyship with Indigenous leaders, communities and individuals. Prioritising the involvement, collaboration and empowerment of Indigenous communities and leadership are critical to successful transformation of healthcare in Indigenous communities. Locally determined priorities and solutions can be enacted to meet community and individual needs, and advance health attainment. This Practice contribution will introduce community engagement principles, and then relate examples of health system, health service and promotion programmes, and provider approaches that have successfully embodied these principles to work in partnership with and empower Indigenous communities to attain health and wellness.

\section{COMMUNITY ENGAGEMENT PRINCIPLES SUPPORTING EMPOWERMENT}

Frameworks from the public engagement literature conceptualise a spectrum of community engagement. Approaches of 'Inform' and 'Consult' perpetuate tokenistic and insincere interactions, with those dominant retaining power and decision-making over the processes and directions enacted. In contrast, actions of 'Involve' and 'Collaborate' represent increasing meaningful community engagement by committing to the inclusion of those affected by the decision and initiative, whereby 'Empower' secures community ownership of the process and ensures power for setting direction and leading initiatives. ${ }^{11}$ This framework is aligned with typology proposed by Pretty ${ }^{12}$ and Wagemakers et al ${ }^{13}$ and adapted by Snijder et al for application to studies evaluating Australian Indigenous community development projects. ${ }^{14}$ Here, higher order activities of interactive participation (reflecting partnership and increased community control over implementation) and selfmobilisation (community generated in its entirety and with community-driven decision-making around involvement of outsiders) reflect the desired levels of engagement between Indigenous leadership, communities and individuals when interacting and working with health systems leadership, services and providers.

To demonstrate structural, systemic and providerlevel interactions privileging community engagement at its highest forms, ${ }^{15}$ examples from Canada, the USA, Australia and New Zealand are summarised here. These demonstrations were selected opportunistically based on availability of information in peer-reviewed publications, inclusions in reports or organisational websites, and limited to a few examples at each of health systems, services and provider levels. While the stories are undoubtedly best shared by those involved in the creation of these innovations, and their outcomes by those who engage in the initiatives, publicly available descriptions were used and interpreted from the lens of a health systems researcher and clinician of Indigenous descent.

\section{LEADERSHIP AND COMMUNITY EMPOWERMENT IN A SELF- DETERMINED HEALTH SYSTEM}

The First Nations Health Authority in British Columbia was officially launched in 2013 following the signing of the 'British Columbia Tripartite Framework Agreement on First Nation Health Governance' in 2011. ${ }^{15}$ This Health Authority was born from the 'Tripartite First Nations Health Plan ${ }^{16}$ developed between the First Nations Leadership Council (representing the British Columbia Assembly of First Nations, the First Nations Summit and the Union of British Columbia Indian Chiefs), the Government of Canada and the Government of British Columbia. As shared in these documents, First Nations leadership advocated for decades to government representatives that fundamental change was required to improve the health status of First Nations people. Propelled by critical court rulings and agreements, ultimately negotiations to transition and transfer health programme and service responsibilities to the First Nations Health Authority were completed, leading to a health system governed by First Nations individuals and communities that interdigitates with the provincial and regional services available in that province. The Authority is also transforming programmes and services, whereby they are reoriented to local community needs. The directions are provided by communities leading the discussions at community engagement hubs, regional caucus sessions and annual forums. ${ }^{17}$

\section{HEALTH SERVICES THAT MEET INDIGENOUS APPROACHES TO HEALTH AND WELLNESS}

Indigenous peoples conceptualise health from the perspective of a balance between physical, mental, emotional and spiritual wellness, and with extensions beyond the individual person to also reflect family and community wellness. Colonial structures reinforce silos of ministries and services that do not connect or interact despite the need for these to align to resolve or mitigate gaps in health outcomes. Khoury's description of the formation and development of Aboriginal CommunityControlled Health Services in Australia exemplifies a health service that approaches health from a wholistic perspective, and that is Indigenous community driven. ${ }^{18}$ The Indigenous community in the Redfern suburb of Sydney established their system to provide a social approach to health. Born of volunteer health service provision, this service from the beginning led advocacy and education of non-Indigenous persons and agencies, provided cultural supports, worked across health and 
social services sectors, provided health education and promotion activities and responded to emerging health crises in community. All aspects of physical, mental, emotional and spiritual health are attended to with empowerment and affirmation of Indigenous identity and leadership.

A second example of this is the Kõkua Kalihi Valley Comprehensive Family Services which serves Native Hawaiians. Kõkua Kalihi Valley began as a health centre initiated to promote healing and reconciliation through medical and dental services. Under community direction and a cultural approach to health, the Pilinahā Framework for Health, which relates the connections vital for health, has been employed throughout the entire organisation, ${ }^{19}$ and Kõkua Kalihi Valley expanded to being a full primary healthcare service which provides social supports and innovative environmental and physical activity promotion initiatives. ${ }^{20}$

\section{COMMUNITY VALUES EMBEDDED IN HEALTH PROMOTION AND INTERVENTION PROGRAMMES}

The He Pikinga Waiora (Enhancing Wellbeing) Implementation Framework was developed for chronic disease interventions with Māori populations in New Zealand. ${ }^{21}$ The theoretical basis of the framework, Kaupapa Māori, ${ }^{22}$ reflects Indigenous knowledge, cultural protocol, methods and philosophy. The interventions are then centred on self-determination and local context priorities, with overlap of western concepts of implementation science associated with positive implementation outcomes.

The Public Health Agency of Canada undertook an activity, called the 'Canadian Best Practices Initiative', to compile promising health promotion and chronic disease interventions throughout the nation. ${ }^{23}$ The Agency supported gathering Indigenous expert opinion to inform the creation of a measurement framework, 'Ways Tried and True', that incorporates Indigenous values in interventions. Six criteria were identified, reflecting the extent to which the intervention was (1) community based, reflecting the degree to which Indigenous community members, service providers, community leaders and elders were involved in the planning, design, delivery, adaptation and evaluation of the intervention; (2) wholistic, with this approach considering wellness, implementation environments, the recipients of the intervention and the involvement of cross-sector departments; (3) involving Indigenous cultural knowledge, incorporating values, culture, shared experiences and the principles of the community/group in which the intervention would operate; (4) building on community strengths and needs, identifying available resources in the implementation environment and building in mechanisms to leverage strengths and fill gaps; (5) partnering and collaborating with external organisations and institutions, and allies; (6) effective at meeting its goals. With this in mind, the report highlights several preventive and health maintenance interventions, including the Kahnawake Schools Diabetes Prevention Project, the Kainai Ever Active Schools and the Little Salmon Carmacks First Nation Greenhouse \& Farm as programmes that best reflect these criteria. More recently, the experience of care delivery in the Niiwin Wendaanimak Four Winds Wellness Program for homeless and at-risk Indigenous populations in Toronto has been described..$^{24}$ Cultural safety has been achieved through Indigenous leadership, with access to activities that promote wellness and community building, inclusivity and harm reduction in a non-judgmental space with respect for dignity, autonomy and kinship.

\section{HEALTH SERVICE PROVISION APPROACHES WITH INDIVIDUALS, FAMILIES AND COMMUNITIES}

Changing physician approaches to communication and care provision is a fundamental need to attain empowerment of Indigenous patients. As exemplified in diabetes ${ }^{25}$ and arthritis, ${ }^{26}$ Indigenous patients have long experienced insufficient physician preparation in understanding the social and cultural contexts of patients' existence. In the 'Educating for Equity' continuing medical education intervention which was developed by an Indigenous-led team, ${ }^{27}$ healthcare providers are taught how to recentre relationship building with their patients, and engage in cultural aspects to support care engagement. ${ }^{28}$ This session goes beyond cultural awareness and competency training, which provide basic instruction on culture and respectful interactions, by providing strategies to clinicians on how to be advocates and address structural barriers to care.

Historically, paternalistic therapeutic approaches in medicine removed decision-making power from patients, and negated their preferences for treatment as well as values. In shared decision-making strategies, providers and patients collaborate to decide on the way forward using communication and decision-making supports. Shared decision-making yields better concordance with patient values, and informational needs can be met. The Minwaashin Lodge partnered with non-Indigenous researchers to adapt the Ottawa Personalized Decision Guide with Indigenous patients, and use it with decision coaching. The adaptation resulted in a tool that better met decision-making needs, supported health literacy, allowed for incorporation of experiences and that could be used as a talking guide when working with a decision coach. ${ }^{29}$ Further work is underway to field test this approach in cancer decision-making. ${ }^{30}$

There is a need for welcoming and supporting the incorporation of traditional practices in healthcare plans. Ongoing privileging of western evidence base in medicine, either through provider hesitancy of accepting the benefit of Indigenous healing practices in maintaining health ${ }^{31}$ or through not funding Indigenous practices, does not align with critical statements by the United Nations, ${ }^{10}$ nor the Truth and Reconciliation Commission 
of Canada. ${ }^{32}$ There are increasing opportunities provided within mainstream health services to access traditional practices. The manuscript by Redvers et al provides a summary of traditional practice offerings funded in Ontario hospitals, including access to traditional ceremonies, elders and healers. ${ }^{33}$ The Indian Health Service in the USA provides a list of cultural and traditional healing activities supported through the organisation. ${ }^{34}$ It is critical that healthcare providers equally privilege these activities as part of healthcare plans.

\section{CONCLUSIONS}

Imposition of colonial healthcare delivery on Indigenous peoples is largely perpetuated in the present-day system and it is increasingly recognised that 'more of the same' will not result in substantive improvements in Indigenous health status. The examples shared here are demonstrations of where Indigenous community-empowered actions have made substantive changes in health structures (the First Nations Health Authority), health services (Aboriginal Community-Controlled Health Services and Kõkua Kalihi Valley) and health promotion programmes (He Pikinga Waiora and Ways Tried and True) to support health and wellness in communities and Indigenous peoples. We also highlight health organisations that have embraced incorporation of traditional healing, and strategies through education and clinical tools where providers have actualised a new way of healthcare delivery, with accountability to those who seek its services.

The examples provided here can provide ideas and guidance on what is required to achieve a healthcare delivery reset. In the spirit of cultural humility, readers are encouraged to engage in reading the original references, and undertake a reflective exercise to consider how these initiatives and changes have come about, and how they can contribute within their roles and privileges. Common elements to the examples are Indigenousdriven leadership to advocate for the changes; creation of culturally aligned structures, services and programmes; and responding to health needs in the local context. As colonial health structures remain in place, mainstream healthcare providers and organisations accepted an allyship role in empowering Indigenous community ownership and delivery of these services. Allyship should not be approached as simply 'improving' or 'helping' others; as expressed by Mitchell $e t$ al, allyship implies respectful relationship building and addressing power imbalances. ${ }^{35}$ What is empowering of others is supporting but not leading, verifying the potential impact of actions before taking them, demonstrating humility and reflexiveness and promoting decolonisation processes internally and externally in longitudinal fashion. Aligned with antiracism activities, colonial health system leadership and providers have a clear role in resetting health service and healthcare delivery, while ceasing to be complicit in the injustices and inequities in healthcare systems and perpetuating health inequities.
Contributors $\mathrm{CB}$ designed the manuscript, assembled relevant references and drafted and finalised the manuscript.

Funding This study was funded by the Institute of Aboriginal Peoples Health (grant number: FDN 143284)

Competing interests None declared.

Patient consent for publication Not required.

Provenance and peer review Not commissioned; externally peer reviewed.

Data availability statement There are no data in this work.

Open access This is an open access article distributed in accordance with the Creative Commons Attribution Non Commercial (CC BY-NC 4.0) license, which permits others to distribute, remix, adapt, build upon this work non-commercially, and license their derivative works on different terms, provided the original work is properly cited, appropriate credit is given, any changes made indicated, and the use is non-commercial. See: http://creativecommons.org/licenses/by-nc/4.0/.

\section{ORCID iD}

Cheryl Barnabe http://orcid.org/0000-0003-3761-237X

\section{REFERENCES}

1 United Nations Permanent Forum on Indigenous Issues. Factsheet: United nations.

2 First Nations Health Authority. Our history, our health. Available: https://www.fnha.ca/wellness/our-history-our-health [Accessed 07 Dec 2020].

3 Waldram JB, Herring DA, Young TK. Aboriginal health in Canada: historical, cultural and epidemiological perspectives. 2 ed. Toronto, ON: University of Toronto Press Incorporated, 2006.

4 Blyton G. Healthier times?: revisiting Indigenous Australian health history. Health History 2009;11:116-35.

5 Reid P, Cormack D, Paine S-J. Colonial histories, racism and healthThe experience of Māori and Indigenous peoples. Public Health 2019;172:119-24.

6 Monavvari AA, Brady L, Harper L, et al. Shifting traditional healthcare paradoxes-The case for true system transformation. Healthc Manage Forum 2020;33:259-64.

7 Tremblay M-C, Graham J, Porgo TV, et al. Improving cultural safety of diabetes care in Indigenous populations of Canada, Australia, New Zealand and the United States: a systematic rapid review. Can J Diabetes 2020;44:670-8.

8 Stanford J, Charlton K, McMahon A-T, et al. Better cardiac care: health professional's perspectives of the barriers and enablers of health communication and education with patients of Aboriginal and Torres Strait Islander descent. BMC Health Serv Res 2019;19:106.

9 Allan B, Smylie J, Peoples F. Second class treatment: the role of racism in the health and well-being of Indigenous peoples in Canada. Toronto, ON: Wellesley Institute, 2015.

10 United Nations. United nations Declaration on the rights of Indigenous peoples, 2007.

11 In:Faulkner WBeltane E, ed. Dialogue in public engagement: a Handbook. Edinburgh: University of Edinburgh, 2011.

12 Pretty JN. Participatory learning for sustainable agriculture. World Dev 1995;23:1247-63.

13 Wagemakers A, Corstjens R, Koelen M, et al. Participatory approaches to promote healthy lifestyles among Turkish and Moroccan women in Amsterdam. Promot Educ 2008;15:17-23.

14 Snijder M, Shakeshaft A, Wagemakers A, et al. A systematic review of studies evaluating Australian Indigenous community development projects: the extent of community participation, their methodological quality and their outcomes. BMC Public Health 2015;15:1154.

15 Greenwood M. Modelling change and cultural safety: a case study in northern British Columbia health system transformation. Healthc Manage Forum 2019;32:11-14.

16 The First Nations Leadership Council, Government of Canada, Columbia GoB. Tripartite first nations health plan, 2007.

17 First Nations Health Authority. Our story: the Made-in-BC tripartite health transformation journey. produced for the assembly of first nations, 2013.

18 Khoury P. Beyond the biomedical paradigm: the formation and development of Indigenous community-controlled health organizations in Australia. Int J Health Serv 2015;45:471-94.

19 Odom Sharon Ka'iulani, Jackson P, Derauf D, et al. Pilinahā: an Indigenous framework for health. Curr Dev Nutr 2019;3:32-8.

20 Hamamoto MH, Derauf DD, Yoshimura SR. Building the base: two active living projects that inspired community participation. $\mathrm{Am} \mathrm{J}$ Prev Med 2009;37:S345-51. 
21 Oetzel J, Scott N, Hudson M, et al. Implementation framework for chronic disease intervention effectiveness in Māori and other Indigenous communities. Global Health 2017;13:69.

22 Smith LT, Reid P, Development MR. Kaupapa Maori principles and practices: a literature review. International Research Institute for Maori and Indigenous Education, 2000.

23 Public Health Agency of Canada. Ways Tried and true: Aboriginal methodological framework for the Canadian best practices initiative. Ottawa, ON, 2015.

24 Firestone M, Syrette J, Jourdain T, et al. "I feel safe just coming here because there are other Native brothers and sisters": findings from a community-based evaluation of the Niiwin Wendaanimak Four Winds Wellness Program. Can J Public Health 2019;110:404-13.

25 Jacklin KM, Henderson RI, Green ME, et al. Health care experiences of Indigenous people living with type 2 diabetes in Canada. CMAJ 2017;189:E106-12.

26 Thurston WE, Coupal S, Jones CA, et al. Discordant Indigenous and provider frames explain challenges in improving access to arthritis care: a qualitative study using constructivist grounded theory. Int $J$ Equity Health 2014;13:46.

27 Crowshoe LL, Henderson R, Jacklin K, et al. Educating for equity care framework: addressing social barriers of Indigenous patients with type 2 diabetes. Can Fam Physician 2019;65:25-33.

28 Crowshoe LL, Han H, Calam B, et al. Impacts of educating for equity workshop on addressing social barriers of type 2 diabetes with Indigenous patients. J Contin Educ Health Prof 2018;38:49-59.
29 Jull J, Giles A, et al, Minwaashin Lodge, The Aboriginal Women's Support Centre. Cultural adaptation of a shared decision making too with aboriginal women: a qualitative study. BMC Med Inform Decis Mak 2015;15:1

30 Jull J, Mazereeuw M, Sheppard A, et al. Tailoring and field-testing the use of a knowledge translation peer support shared decision making strategy with first nations, Inuit and Métis people making decisions about their cancer care: a study protocol. Res Involv Engagem 2018;4:6.

31 Logan L, McNairn J, Wiart S, et al. Creating space for Indigenous healing practices in patient care plans. Can Med Educ $J$ 2020;11:e5-15.

32 Truth and Reconciliation Commission of Canada. Truth and reconciliation Commission of Canada: calls to action. Winnipeg, MB, 2015.

33 Redvers N, Marianayagam J, Blondin Be'sha. Improving access to Indigenous medicine for patients in hospital-based settings: a challenge for health systems in northern Canada. Int J Circumpolar Health 2019;78:1589208.

34 Indian Health Service. Culturally relevant best practices. Available: https://www.ins.gov/mspi/bppinuse/cultural/ [Accessed 22 Nov 2020].

35 Mitchell TL, Thomas D, Smith JA. Unsettling the Settlers: Principles of a Decolonial Approach to Creating Safe(r) Spaces in Post-secondary Education. Am J Community Psychol 2018;62:350-63. 